\title{
Kajian Minyak Solar Dari Hasil Penyulingan Tradisional (Studi kasus pertambangan minyak tradisional di Desa Pasir Putih Aceh Timur)
}

\author{
Pribadyo $^{1}$, T. Kausar ${ }^{2}$ \\ 1) Jurusan Mesin, Fakultas Teknik, Universitas Teuku Umar \\ 2) Staf, Universitas Teuku Umar \\ Jl. Alue Peuyareng, Meureubo Aceh Barat 23561 \\ Email: dyo_1806@yahoo.co.id
}

\begin{abstract}
Absrak
Solar merupakan salah satu komuditi yang sering digunakan oleh masyarakat luas terutama di indonesia. Hampir seluruh masyarakat Indonesia memakai solar untuk sarana sehari - hari terutama untuk bahan bakar kendaraan. Untuk solar sendiri banyak yang diproses atau di olah di pabrik-pabrik besar yang salah satu nya diproduksi oleh PT. Pertamina. Kualitas minyak solar ditentukan oleh angka Cetana. Tujuan dari penelitian ini untuk mengetahui kualitas minyak yang dihasilkan dari penyulingan tradisional yang dilakukan oleh masyarakat Rantau Panjang Peurelak Aceh Timur dan kemudian dibandingkan dengan minyak solar standart mutu SNI. Pengujian dilakukan dengan menggunakan alat ukur Piknometer untuk berat jenis (bj) dan Oktanometer Shatox untuk pengujian Angka setana. Berdasarkan Hasil pengujian minyak solar hasil penyulingan tradisional nilai berat jenis adalah sebesar $877,6 \mathrm{Kg} / \mathrm{m}^{3}$ dan minyak solar standart mutu SNI berat jenis nya adalah sebesar $815-860 \mathrm{Kg} / \mathrm{m}^{3}$. Dari hasil pengujian minyak solar hasil penyulingan tradisional nilai angka setana adalah sebesar 48 dan minyak solar standart mutu SNI nilai angka setana adalah sebesar 48-51. Maka dapat disimpulkan angka setana minyak solar hasil penyulingan tradisional memenuhi Standart Nasional Indonesia sehingga layak untuk digunakan.
\end{abstract}

Kata kunci: Peyulingan tradisional, angka Cetana, Minyak solar

\section{PENDAHULUAN}

Pengetahuan mengenai minyak bumi sangat penting untuk kita ketahui, mengingat minyak bumi adalah suatu sumber energi yang tidak dapat di perbaharui, sedangkan penggunaan sumber energi ini dalam kehidupan kita sehari-hari cakupannya sangat luas dan cukup memegang peranan penting atau menguasai hajat hidup orang banyak. Sebagai contoh minyak bumi di gunakan sebagai sumber energi yang banyak di gunakan untuk memasak, sebagai bahan bakar kendaraan bermotor, industi, dan sebagainya masih mengandalkan bensin dan solar..

Solar merupakan salah satu komuditi yang sering digunakan oleh masyarakat luas terutama di Indonesia. Hampir seluruh masyarakat Indonesia memakai solar untuk sarana sehari - hari terutama untuk bahan bakar kendaraan. Untuk solar sendiri banyak yang di proses atau di olah di pabrik - pabrik besar yang salah satu nya PT. Pertamina. Proses pengolahan nya pun di lakukan dengan kapasitas besar mulai dari pengeboran sampai ke penyulingan minyak nya. Untuk penelitian yang kami lakukan ini, kita pelajari proses penyulingan dengan kapasitas kecil atau proses penyulingan manual yang dilakukan di suatu tambang masyarakat, yang terletak di kawasan Aceh Timur, Kecamatan Rantau Panjang Peureulak, Desa Pasir Putih. Dalam proses penyulingan kita akan mendapatkan 


\section{Jurnal Mekanova}

Vol 4. No. 1, April 2018

ISSN : 2502-0498

gas (potrelium), minyak bensin (gasolin), minyak tanah (kerosin), minyak diesel dan residu dari hasil penyulingan manual tersebut.

Dari uraian dan latar belakang di atas maka kajian kualitas minyak solar yang diperoleh dari hasil penyulingan secara tradisional perlu untuk dilakukan.

Pengolahan minyak bumi

\section{LANDASAN TEORI}

Minyak bumi biasanya beradai 3-4 Km di bawah permukaan. Untuk mengambil minyak bumi tersebut kita harus membuat sumur bor yang telah di sesuaikan kedalamannya. Pengolahan minyak bumi dilakukan melalui distilasi bertingkat, dimana minyak mentah dipisahkan ke dalam kelompok-kelompok dengan titik didih yang ditunjukkan pada gambar 2.1 sebagai berkut:

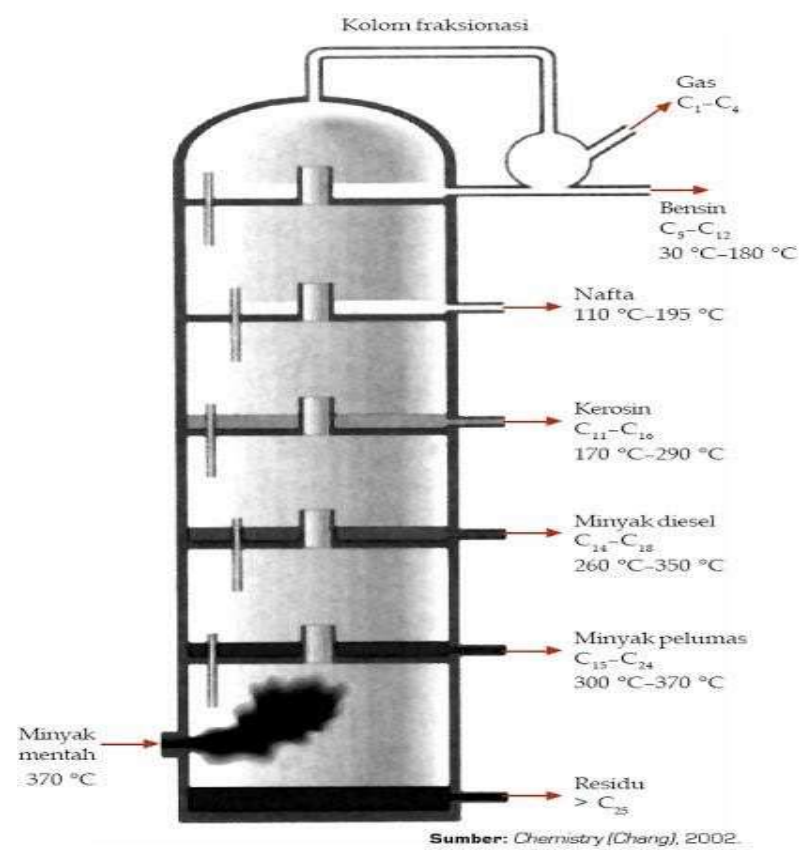

Sumber : http://ichsanrizqia17994.weebly.com/uploads.rig.jpg

Syarat utama agar terjadinya proses destilasi adalah adanya perbedaan komposisi antara fase cair dan fase uap. Dengan demikian apabila komposisi fase cair dan face uap sama maka proses destilasi tidak mungkin dilakukan. Proses destilasi pada kilang minyak bumi merupakan pengolahan secara fisika yang primer sebagai awal dari semua proses memproduksi BBM (Bahan Bakar Minyak).

Solar

Solar adalah hasil dari pemanasan minyak bumi antara $250-340^{\circ} \mathrm{C}$, dan merupakan bahan bakar mesin diesel. Solar tidak dapat menguap pada suhu tersebut dan bagian minyak bumi lainnya akan terbawa ke atas untuk diolah kembali. Umumnya solar mengandung belerang dengan kadar yang cukup tinggi. Kualitas minyak solar dinyatakan dalam bilangan setana. Ngka setana adalah tolak ukur kemudhan menyala atau terbakarnya suatu bahan bakar dida;am mesin diesel. Angka setana produk solar yang ada di pasaran adalah 48. Dengan kandungan sulfur maksimumnya mencapai 5000 ppm.

Sifat utama dari solar 


\section{Jurnal Mekanova \\ Vol 4. No. 1, April 2018 \\ ISSN : 2502-0498}

Bahan bakar diesel biasa juga disebut light oil atau solar, adalah suatu campuran dari hydrocarbon yang telah di distilasi setelah bensindan minyak tanah dari minyak mentah pada temperatur 200 sampai 340. Sebagian besar solar digunakan untuk menggerkkan mesin diesel. Bahan bakar diesel mempunyai sifat utama yaitu:

1. Tidak berwarna atau sedikit kekuning-kuningan dan berbau.

2. Encer dan tidak menguap dibawah temperatur normal.

3. Mempunyai titik nyala tinggi ( $40 \mathrm{C}-100 \mathrm{C}$ ).

4. Terbakar spontan pada 350 , sedikit dibawah temperatur bensin.

5. Mempunyaiberat jenis $0,82-0,86$.

6. Menimbulkan panas yang besar (sekitar $10.500 \mathrm{kcal} / \mathrm{kg}$ ).

7. Mempunyai kandungan sulfur lebih besar dibanding bensin.

8. Memiliki rantai Hidrokarbon $\mathrm{C}_{14} \mathrm{~s} / \mathrm{d} \mathrm{C}_{18}$.

\section{Syarat-syarat Kualitas Solar}

1. Mudah terbakar

2. Solar harus dapat memungkinkan engine bekerja lembut dengan sedikit knocking.

3. Tetapencer pada suhu dingin sangat (tidak mudah membeku) karena Solar harus tetap cair pada temperatur rendah sehingga engine akan mudah dihidupkan dan berputar lembut.

4. Solar juga berfungsi sebagai pelumas untuk pompa injeksi dan nosel Oleh karena itu harus mempunyai sifat daya pelumas yang baik.

5. Solar harus mempunyai kekentalan yang memadai sehingga dapat disemprotkan oleh injektor.

6. Sulfur merusak pemakaian komponen engine, dan kandungan sulfur solar harus sekecil mungkin.

7. Tidak berubah dalam kualitas, tidak mudah larut selama disimpan.

\section{METODE PENELITIAN}

Penelitian ini dimulai dari studi literatur yaitu pengumpulan data yang bersumber dari buku-buku, jurnal ilmiah dan internet yang berkaitan dengan topik yang diteliti. Studi lapangan yakni dengan melihat langsung proses produksi minyak solar serta wawancara kepada pihak-pihak terkait menyangkut dengan topik yang diteliti. Setelah data-data diperoleh selanjutnya dilakukan analisa data terhadap data literatur dan data lapangan. Bahan uji pada penelitian ini berupa minyak solar yang diperoleh dari pertambangan rakyat yang disuling secara tradisional terletak di Kabupaten Aceh Timur Kecamatan Rantau Panjang Peurelak Desa Pasir Putih yang diperlihatkan pada gambar 3.1 dibawah ini. Pengujian kualitas minyak solar dilakukan di Badan Riset Standart Industri (BARISTAND) Banda Aceh.

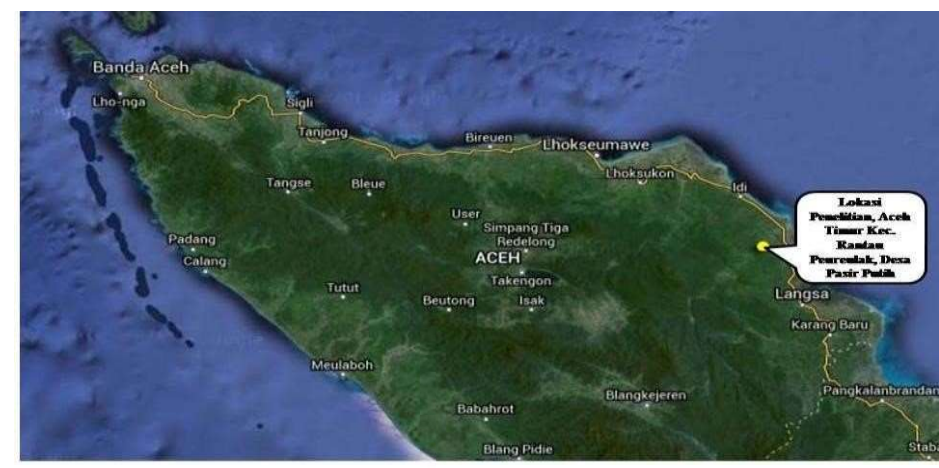




\section{Jurnal Mekanova}

Vol 4. No. 1, April 2018

ISSN : 2502-0498

\section{Bahan dan Alat}

Gambar 3.1. Lokasi penelitian

Sumber:https://www.google.co.id/maps

Bahan yang digunakan adalah minyak mentah (Crude Oil) hasil pengeboran tambang rakyat tradisional yang selanjutnya dilakukan penyulingan selama kurang lebih 2 jam pada suhu $350^{\circ} \mathrm{C}$. Minyak solar sebelum dan sesudah dilakukan peyuingan ditunjukkan pada gambar 3.2 dan 3.3 dibawah ini:

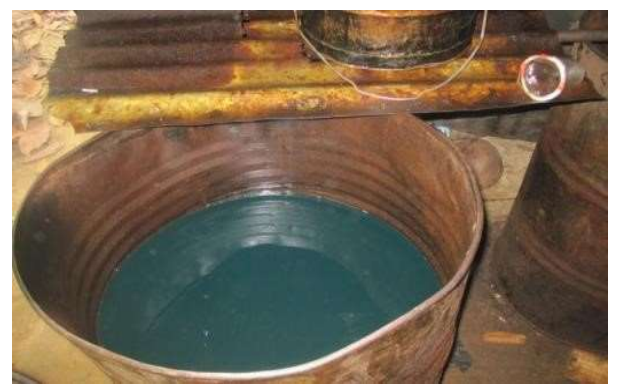

Gambar 3.2 Minyak Mentah

Sumber : Tambang rakyat aceh timur

\section{Alat ukur}

\section{- Piknometere}

Piknometere adalah alat untuk mengukur/menentukan berat jenis suatu zat yang ditunjukkan dalam gambar 3.4 berikut ini:

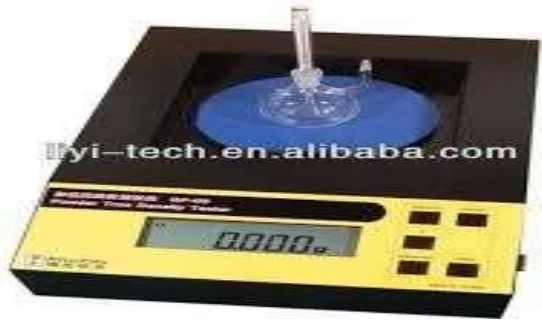

Gambar 3.4 Piknometere

sumberhttp://www.google.com/search?q=piknometer+elektrik

\section{- Oktanometer Shatox}

Oktanometer Shatox adalah alat untuk mengukur/menentukan angka oktana pada bensin dan angka cetana pada solar yang ditunjukkan pada gamar 3.5 berikut ini:

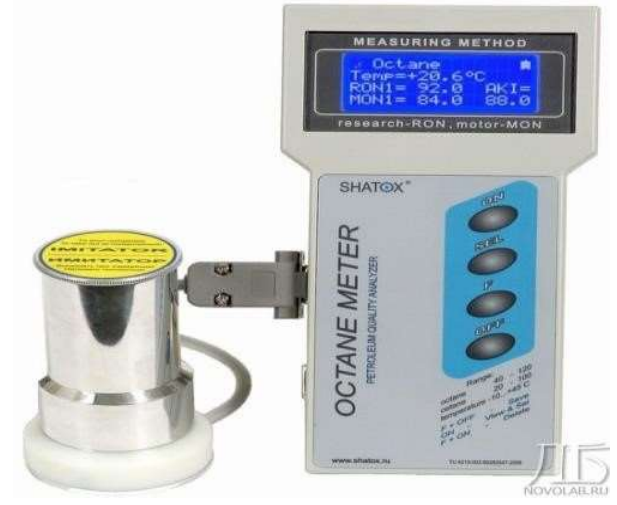


Jurnal Mekanova

Vol 4. No. 1, April 2018

ISSN : 2502-0498

Gambar 3.5 Piknometere

sumber :http://www.google.com/search?q=oktanometer+shatox

\subsection{Diagram alir penelitian}

Flow chart penelitian ditunjukkan pada gambar 3.6 berikut ini:

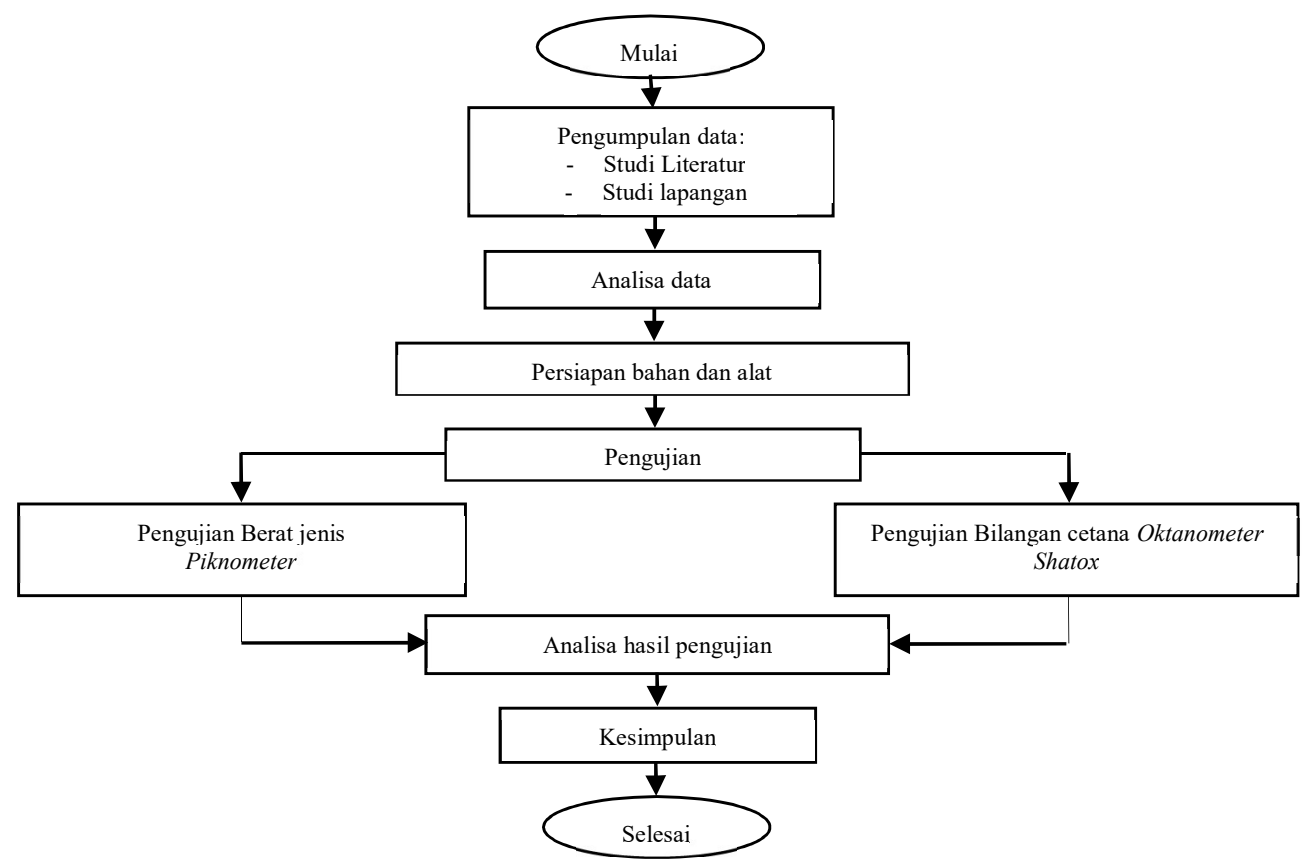

Gambar 3.5 Diagram alir penelitian

\section{HASIL DAN PEMBAHASAN}

\section{4.l Hasil pengujian Berat Jenis (bj)}

Berdasarkan hasil dari Pengujian berat jenis minyak solar dengan menggunakan alat penyulingan tradisional rakyat Aceh timur dengan menggunakan suhu $20^{\circ} \mathrm{C}$ hasilnya dapat dilihat pada grafik 4.1 dan tabel 4.1 dibawah ini : 
Jurnal Mekanova

Vol 4. No. 1, April 2018

ISSN : 2502-0498

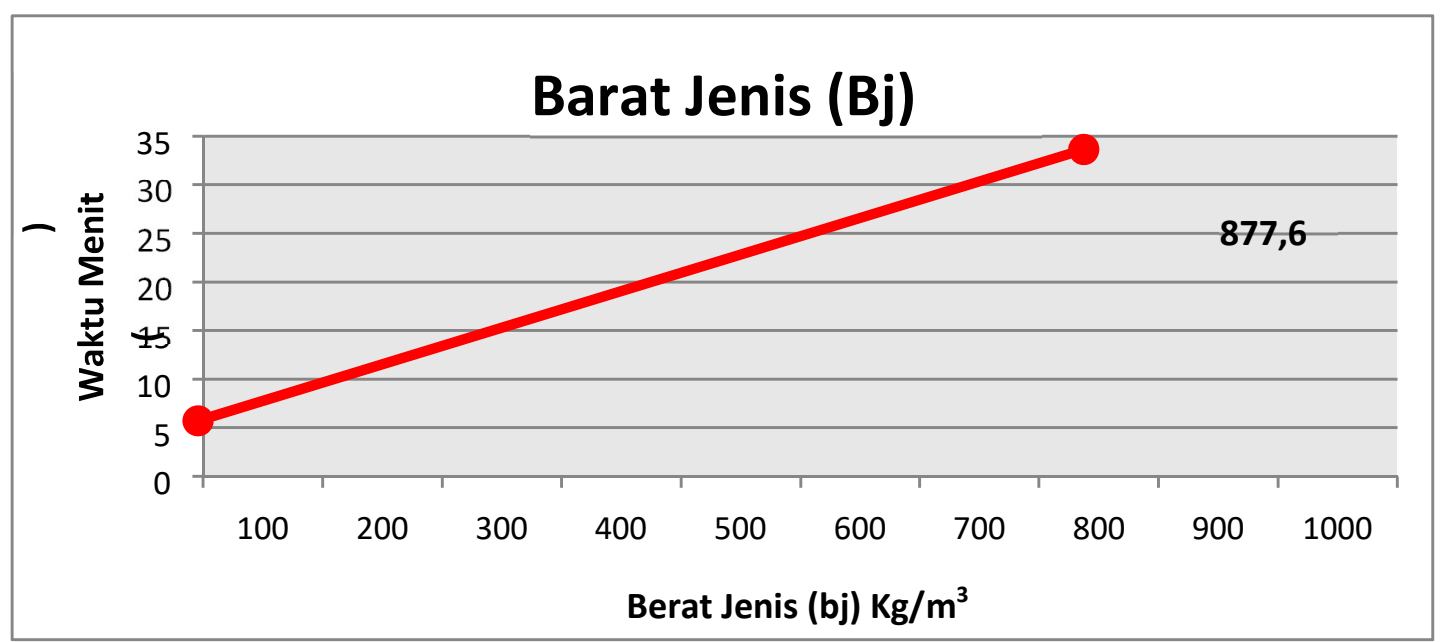

Sumber: Hasil Penelitian

Tabel 4.1 Berat jenis (bj)

\begin{tabular}{|c|c|c|c|c|}
\hline No. & Parameter Uji & Satuan & MetodeUji & HasilUji \\
\hline 1. & BeratJenis $20^{\circ} \mathrm{C}$ & $\mathrm{Kg} / \mathrm{m}^{3}$ & Piknometri & 877,6 \\
\hline
\end{tabular}

Sumber : Hasil Penelitian

\subsection{Hasil Pengujian Berat Jenis (bj) Standart mutu SNI.}

Pengujian berat jenis minyak solar berdasarkan standart mutu SNI dengan menggunakan suhu $20^{\circ} \mathrm{C}$ dapat dilihat pada grafik 4.2 dan tabel 4.2 dibawah ini :

\section{Grafik 4.2 Pengujian standart mutuS NI}

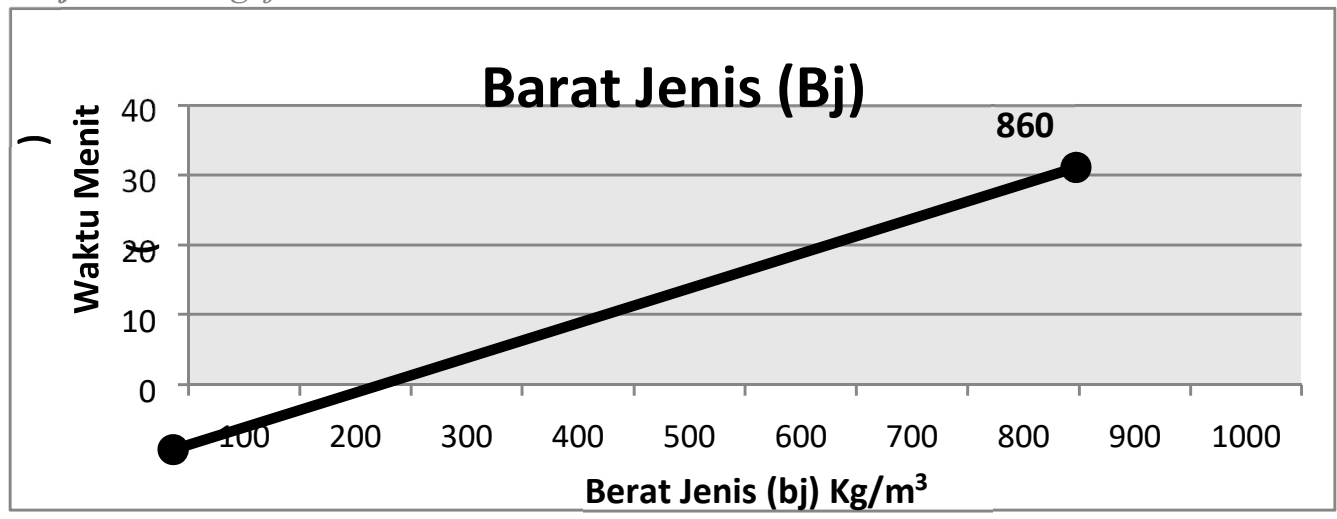

Sumber $\quad$ :http://sisni.bsn.go.id/index.php/sni_main/sni/detail_sni/9516

Tabel 4.2Berat jenis standart SNI

\begin{tabular}{|c|c|c|c|c|}
\hline No. & Parameter Uji & Satuan & MetodeUji/ASTM & HasilUji \\
\hline 1. & BeratJenis $20^{\circ} \mathrm{C}$ & $\mathrm{Kg} / \mathrm{m}^{3}$ & D 613-95 & $815-860$ \\
\hline
\end{tabular}

Sumber : http://sisni.bsn.go.id/index.php/sni_main/sni/detail_sni/9516

\subsection{Perbandingan (bj) solar tradisionaldan solar standarmutu SNI.}


Jurnal Mekanova

Vol 4. No. 1, April 2018

ISSN : 2502-0498

Berdasarkan hasil dari pengujian minyak tradisional dan minyak standart mutu SNI dengan menggunakan suhu $20^{\circ} \mathrm{C}$,Maka hasilnya dapat dilihat pada grafik 4.3 dan tabel 4.3 dibawah ini.

Grafik 4.3Hasil Data perbandingan

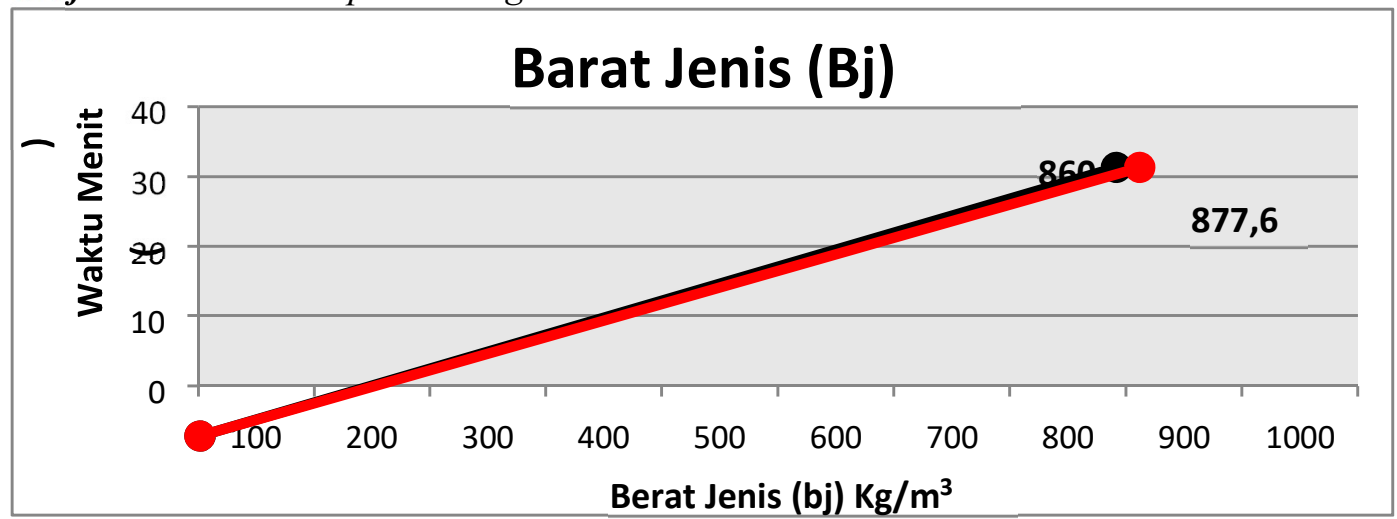

Sumber: Hasil Penelitian

Tabel 4.3 Perbandingan berat jenis tradisional dan standart mutu SNI.

\begin{tabular}{|l|c|l|c|c|c|}
\hline NO. & Parameter Uji & Satuan & MetodeUji/ASTM & HasilUji & Keterangan \\
\hline 1. & $\begin{array}{c}\text { Berat Jenis } \\
20^{\circ} \mathrm{C}\end{array}$ & $\mathrm{Kg} / \mathrm{m}^{3}$ & Piknometri & 877,6 & $\begin{array}{c}\text { Minyaktradisi } \\
\text { onal }\end{array}$ \\
\hline $\begin{array}{c}\text { o. } \\
\text { BeratJenis } \\
20^{\circ} \mathrm{C}\end{array}$ & $\mathrm{Kg} / \mathrm{m}^{3}$ & D 613-95 & $815-860$ & $\begin{array}{c}\text { Data hasil } \\
\text { SNI }\end{array}$ \\
\hline
\end{tabular}

Sumber: Hasil Penelitian

4.5 Hasil pengujian angka setana solar.

Berdasarkan hasil pengujian dari angka setana solar tradisional dan solar standart SNI.Maka nilainya dapat di lihat pada tabel (4.1) dibawah ini; Tabel 4.1Angka Setana.

\begin{tabular}{|c|c|c|c|c|}
\hline NO. & Parameter Uji & Satuan & Metode Uji/ ASTM & Hasil Uji \\
\hline 1. & Angka Cetana & - & Oktanometer Shatox & 48 \\
\hline 2. & Angka Cetana & - & D 613-95 & $48-51$ \\
\hline
\end{tabular}

Sumber : Hasil Penelitian

Pembahasan

Dari proses pengujian sampel minyak solar tradisional adalah sebagai berikut:

1. Dengan bahan uji minyak solar hasil penyulingan tradisional dan menggunakan alat ukur Piknometer dengan suhu $20^{\circ} \mathrm{C}$ dan waktu 30 menit menghasilkan nilai berat jenis (bj) $877,6 \mathrm{~kg} / \mathrm{m}^{3}$.Pada Minyak solar standart mutu SNI menggunakan alat ukur piknometer dengan suhu $20^{\circ} \mathrm{Cdan}$ waktu 30 menit menghasilkan nilai berat jenis (bj) antara 815 sampai 860. 
2. Dengan bahan uji Minyak hasil penyulingan tradisional dengan menggunakan alat ukur oktanometer shatox menghasilkan nilai 48. Pada minyak solar standart mutu SNI nilainya adalah sebesar 48 sampai 51.

Kualitas minyak solar ditentukan dangan Angka Setana, minyak solar hasil penyulingan tradisional nilainya termasuk dalam kualitas Angka Setana minyak solar standart mutu SNI.

\section{KESIMPULAN}

Dari penelitian yang telah dilakukan, maka dapat disimpulkan sebagai berikut:

1. Berdasarkan Hasil pengujian minyak solar hasil penyulingan tradisional nilai berat jenis adalah sebesar $877,6 \mathrm{Kg} / \mathrm{m}^{3}$ dan minyak solar standart mutu SNI berat jenis nya adalah sebesar $815-860 \mathrm{Kg} / \mathrm{m}^{3}$.

2. Dari hasil pengujian minyak solar hasil penyulingan tradisional nilai angka setana adalah sebesar 48 dan minyak solar standart mutu SNI nilai angka setana adalah sebesar 48-51.

3. Maka berat jenis dan angka setana minyak solar hasil penyulingan tradisional Memenuhi standart SNI.

\section{SARAN}

Guna kesempurnaan yang diperoleh disarankan untuk penelitian selanjutnya agar dapat dicari Perbandingan alat pengolahan minyak Solar secara tradisional dengan Standar SNI.

\section{DAFTAR PUSTAKA}

1. Zuhdan, Ahmad. 1997. Crude oil (Minyak Mentah). PPT MIGAS : Cepu.

2. Purba, Michael. 2006. KIMIA 1B. Jakarta: Erlanggahttp://acehforum.or.id

3. Austin, T. George. 1985. Shreves Chemical Process Industries. Mc Graw Hill Book Company.

4. Indri P., ST., MT, Cylirilla, Tugas Kimia Pembakaran, Kimia Teknik, 2011.

5. Hambali, Erliza., Siti, M., Armansyah, H.M., Abdul, W.P dan Roy, H., TekonologiBioenergi, AgroMediaPustaka, Jakarta, 2007.

- http://feryhariyantoo.blogspot.co.id/2013/07/minyak-solar- sifatkegunaandanjenis.html

- http://duniagalery.blogspot.co.id/2015/06/jenis-bahan-bakar-dan-standar-mutu.

- http://yu2n-sevenfoldism.blogspot.co.id/2012/04/piknometer-dan-neraca.html

- http://shatox.com/catalog/i-2-oktanometer-SX-100m.html5

- http://ukmsttmigas.blogspot.co.id/2013/05/signifikasi-pengujian-minyak-solar.html

- http://www.pipercomex.com/2011/10/apa-itu-cetane-number.html 
Jurnal Mekanova

Vol 4. No. 1, April 2018

ISSN : 2502-0498 